REVIEW

\title{
The approach to patients with "non-epileptic seizures"
}

\author{
J D C Mellers
}

Postgrad Med J 2005;81:498-504. doi: 10.1136/pgmj.2004.029785

Up to one fifth of patients who present to specialist clinics with seizures do not have epilepsy. The majority of such patients suffer from psychologically mediated episodes; dissociative seizures, often referred to as "non-epileptic seizures". This paper describes the diagnostic evaluation of seizure disorders, including clinical assessment and the role of special investigations. The organic and psychiatric imitators of epilepsy are outlined and findings on psychiatric assessment are reviewed. This group of patients often proves difficult to engage in appropriate treatment and an approach to explaining the diagnosis is described. As yet there are no controlled trials of treatment in this disorder but preliminary evidence suggests cognitive behavioural therapy is both a rational and promising way forward.

Correspondence to:

Dr J D C Mellers,

Department of

Neuropsychiatry, Room

32, Outpatient

Department, Maudsley

Hospital, Denmark Hill,

London SE5 8AZ, UK

Submitted 15October 2004 Accepted

14 December 2004
U p to one in five patients with apparently intractable epilepsy referred to specialist centres are found to have no organic cause for their seizures. ${ }^{1-4}$ It has been widely supposed that this high prevalence reflects referral bias but a recent community based study found a similar proportion among patients with recent onset seizures. ${ }^{5}$ This group of patients suffer from psychologically mediated paroxysmal behavioural disturbances that are often dramatic, alarming for bystanders, and all too easily mistaken for epilepsy. Diagnostic errors are the rule rather than an exception. Most patients are treated for epilepsy for several years ${ }^{6}$ and by the time the correct diagnosis is made they will commonly have taken more antiepileptic drugs (AEDs) at higher doses and experience more side effects than an equivalent cohort of patients with epilepsy. ${ }^{8}$ One in 10 patients will present in apparent status epilepticus. ${ }^{78}$ Astonishingly, about one quarter of referrals to a specialist neurological intensive care unit with refractory status were found to have "pseudostatus". ${ }^{10}$

What this disorder should be called has been the subject of considerable debate. Some terms (hysterical seizures, pseudoseizures) are pejorative, unacceptable to patients, ${ }^{11}$ and have largely been abandoned. Others (non-epileptic seizures (NES), non-epileptic attack disorder) merely describe what the condition is not, rather than conveying what it is. Furthermore, these terms have been used with different meanings: the term NES, for example, is sometimes used to refer to the group of neurological, cardiological, and other medical conditions, in addition to psychiatric disorders, which constitute the differential diagnosis for epilepsy, ${ }^{4}$ while on other occasions the term is used as a form of loose shorthand to refer to the psychological attacks alone. ${ }^{12}$ The terms psychogenic NES and functional seizures overcome some of these objections but formal psychiatric classification systems provide clearly defined labels. Unfortunately, though, there are still inconsistencies: thus, within DSM IV ${ }^{13}$ such attacks are classified under somatoform disorder and in ICD $10^{14}$ the diagnostic label "dissociative convulsions", is classified within the group of conversion disorders. It is the latter terminology that will be adopted here.

As we have seen, dissociative convulsions or seizures (DS) are common, the diagnosis is often missed, and when it is patients not only fail to receive appropriate treatment but are subject to unnecessary, costly, ${ }^{15}$ and potentially harmful medical interventions. In considering the management of this disorder we will therefore focus on assessment and diagnosis before considering contemporary approaches to treatment.

\section{CLINICAL ASSESSMENT}

It should be emphasised from the start that epilepsy is primarily a clinical diagnosis. Great care must be taken to establish the precise sequence of events during an attack and history taking is not complete until an eyewitness account has been obtained. The duration of each phase of symptoms, including recovery from the attack, should be determined. Any habitual pattern in the circumstances that trigger attacks should be sought. Patients and eyewitnesses should be prompted for specific symptoms because significant features may not be mentioned spontaneously (for example, psychic and cognitive symptoms, automatisms, occurrence during sleep).

\section{Medical differential diagnosis}

The box lists the medical and psychiatric differential diagnosis for epilepsy (see Cook $^{16}$ and Andermann ${ }^{17}$ for a review). Of medical disorders mistaken for epilepsy syncope is the most common ${ }^{3}$ and in non-specialist settings is the condition most likely to be misdiagnosed as epileptic. It is important to note that tonic or clonic movements may be seen during syncope. ${ }^{18}$ However, characteristic prodromal symptoms (lightheadedness, clammy sweatiness, a sense of receding sound and vision, nausea), associated cardiac symptoms, and a relation in some cases to postural changes or valsalva usually make identifying cases of syncope straightforward. ${ }^{19} 20$ In patients with cerebrovascular disease the

Abbreviations: AED, antiepileptic drug; NES, nonepileptic seizure; DS, dissociative seizure; ES, epileptic seizure; CBT, cognitive behavioural therapy 
differentiation of transient ischaemic attacks from partial seizures may sometimes be difficult. Ischaemic episodes may last for seconds to minutes but usually occur with preserved consciousness, are associated only with a loss of function, and are not followed by more typical epileptic features. A comparatively long duration of symptoms is useful in recognising migraine, migraine equivalents (the latter featuring prodromal symptoms but no headache), ${ }^{21}$ and vertigo. Abnormal startle phenomena, including hyperekplexia, are rare but often mistaken for epilepsy and need to be distinguished from startle induced seizures. ${ }^{1722}$ Paroxysmal movement disorders may be mistaken for epilepsy. ${ }^{23}$ Sudden loss of muscle tone that may produce falls in response to an emotional trigger suggest cataplexy, which is usually found in association with other features of the narcolepsy syndrome (narcolepsy, hypnopompic or hypnogogic hallucinations, and sleep paralysis). Other parasomnias giving rise to complex behavioural episodes arising from sleep may be confused with epileptic automatisms although the former lack any preceding ictus and are usually of comparatively long duration. ${ }^{24}$ Space occupying lesions in the 3rd ventricle may produce intermittent CSF obstruction associated with visual symptoms and are a rare cause of sudden episodes of collapse with loss of consciousness. Metabolic disorders associated with loss of consciousness usually have a protracted time course and are suggested by other features in the history.

\section{Psychiatric differential diagnosis}

Once epilepsy and other organic causes of seizures have been excluded there are three categories of psychiatric diagnoses

\section{The differential diagnosis of epilepsy}

Medical causes of transient neurological dysfunction (with or without loss of consciousness)

- Syncope

- vasovagal

- cardiogenic

- Neurological

- cerebrovascular

- migraine

- vertigo

- cataplexy

- parasomnias

- movement disorders

- startle induced phenomena

- Endocrine and metabolic

- hypoglycaemia

- hypocalcaemia

- hereditary fructose intolerance

- drugs and alcohol

Psychiatric disorders

- Psychiatric disorders that may be mistaken for epilepsy

- panic disorder

- psychosis

- Attention deficit hyperactivity disorder

- Depersonalisation disorder

- Dissociative seizures

- Factitious disorder that must be considered: (1) dissociative seizures; (2) factitious disorder; (3) other psychiatric disorders that have been mistaken for epilepsy. Dealing with the last category first, paroxysmal symptoms of psychiatric disorders may sometimes raise the question of epilepsy. The most common example of this is panic disorder. ${ }^{25}$ Patients may report depersonalisation, derealisation, and tremulousness during panic attacks while partial epileptic seizures may include both emotional and somatic symptoms of anxiety. ${ }^{26}$ Features that are useful in distinguishing the two conditions include a longer duration, cognitive symptoms, and the presence of specific environmental triggers in panic disorder and, in partial seizures, the unique quality of the emotional symptoms ("ictal fear") together with associated more characteristic epileptic features in partial seizures. Paroxysmal symptoms in psychosis may sometimes raise the question of epilepsy but such symptoms (for example, hallucinations) lack the highly stereotyped quality of epileptic phenomena and episodes are usually of long and variable duration. Other psychiatric disorders sometimes confused with epilepsy include depersonalisation disorder and attention deficit hyperactivity disorder in which failing school performance and poor concentration may sometimes raise the possibility of juvenile absence epilepsy.

In most cases, however, the seizures will be the principal symptom and cannot be accounted for by another psychiatric condition. The two diagnostic possibilities are dissociative seizures and factitious disorder distinguished from one another by whether the seizures are thought to arise through unconscious processes (DS) or are deliberately enacted. In factitious disorder the patient is held to be deliberately simulating epilepsy for reasons understandable in terms of their psychological background. It is distinguished from malingering (not a medical diagnosis) in which people are simulating illness for some obvious practical gain (for example, compensation, avoidance of criminal responsibility).

\section{The semiology of dissociative seizures}

A careful history will usually provide sufficient grounds for suspecting DS, which is by far the commonest psychiatric imitator of epilepsy. Since the introduction of video electroencephalographic monitoring (vEEG telemetry) 30 years ago countless studies have compared DS with epilepsy aiming to find clinical features that distinguish one condition from the other. ${ }^{27}$ Unfortunately, no one symptom or sign allows the diagnosis to be made with absolute certainty. Some of the more useful clinical features, together with important "red herrings", are listed in table 1.

Some two thirds of DS involve prominent motor features. The remainder may mimic partial seizures or involve a period of unresponsiveness with little in the way of motor activity. ${ }^{7828} 36374144$ The hallmark of epileptic seizures is that they are brief, temporary changes of neurological function that follow a highly stereotyped pattern from one occasion to the next. Furthermore, epileptic seizures conform to a number of familiar syndromes that have now been clearly defined. $^{45}$ It is any variation from these well described syndromes that will alert the experienced clinician to suspect DS. In addition to recognising an "atypical sequence of events $^{\prime \prime}$ the most helpful objective features distinguishing DS from epileptic seizures are long duration (over two minutes), a gradual onset with motor features that wax and wane throughout the seizure, and, on recovery, evidence that the patient is able to recall events for a period of unresponsiveness. An episode of motionless unresponsiveness (that is reversible) lasting over five minutes is unlikely to have an organic explanation. ${ }^{7}$ Additional features on history that favour (and only that) a diagnosis of DS rather than epilepsy include onset of seizures after the age of 10, a failed response 
Table 1 Some clinical semiological features of epileptic and dissociative seizures

\begin{tabular}{|c|c|c|}
\hline & Dissociative seizures & Epileptic seizures \\
\hline Duration over two minutes & common $^{1728-30}$ & rare \\
\hline *Stereotyped attacks & common $^{73132}$ & common \\
\hline \multicolumn{3}{|l|}{ Motor features } \\
\hline Gradual onset & common $^{728313334}$ & rare \\
\hline Fluctuating course & Common $^{7}$ & very rare \\
\hline Thrashing, violent movements & common $^{28} 35-37$ & rare \\
\hline Side to side head movement & common $^{2935}$ & rare \\
\hline Asynchronous movements & common $^{2938}$ & very rare \\
\hline Eyes closed & common $^{2839}$ & rare \\
\hline Pelvic thrusting & occasional' 2940 & rare \\
\hline Opisthotonus, "arc de cercle" & occasional $^{283141}$ & very rare \\
\hline Automatisms & rare $^{41}$ & common \\
\hline Weeping & occasional $^{42} 43$ & very rare \\
\hline *Incontinence & occasional $^{3544}$ & common \\
\hline \multicolumn{3}{|l|}{ *Injury } \\
\hline Biting inside of mouth & occasional $^{73} 394144$ & common \\
\hline Severe tongue biting $†$ & very rare 73394144 & common \\
\hline Recall for period of unresponsiveness & common $^{1741}$ & very rare \\
\hline \multicolumn{3}{|c|}{$\begin{array}{l}\text { *Three features ("red herrings") that are commonly misinterpreted as evidence for epilepsy have been included in } \\
\text { this table for emphasis. Otherwise the table lists clinical features that are often useful in distinguishing DS from ES. } \\
\text { Figures for frequency of these features are approximate: common }>30 \% \text {; occasional }=10 \%-30 \% \text {; rare }<10 \% \text {; } \\
\text { very rare }<5 \% \text {. Injuries to the tongue in epilepsy usually involve the side of the tongue. Bite injuries to the tip of the } \\
\text { tonque or lip are rare in epilepsy and suggest DS. }{ }^{39}\end{array}$} \\
\hline
\end{tabular}

to AEDs, and the presence of risk factors for DS (including a history of previous unexplained medical symptoms, a psychiatric history, and a history of childhood traumatic experiences-see below). An absence of risk factors for epilepsy is reassuring in making a diagnosis of DS but their presence may be misleading ${ }^{32}$ as, for example, DS are common in patients with learning difficulties (also associated with epilepsy) and a family history of seizures is common in patients with DS. ${ }^{46}$

Between $10 \%$ and $30 \%$ of patients with DS also have epilepsy, 128363841434447 which may create problems in diagnosis and management. A history of multiple seizure types is not a reliable indicator of comorbid epilepsy as some $20 \%$ of patients with DS alone report more than one type of seizure. ${ }^{35}{ }^{36}{ }^{41}$ Special mention should also be made of frontal lobe epilepsy, which is often mistaken for DS. Frontal lobe seizures may involve bizarre emotional and behavioural features highly suggestive of DS. ${ }^{47}$ These include intense emotional reactions, asymmetrical motor posturing, kicking and thrashing, body rocking, side to side head movements, and complex behavioural paroxysms such as pelvic thrusting, undressing, masturbatory activity, and uttering obscenities. Furthermore, despite the complexity of behaviours involved patients will often claim some preservation of awareness during attacks and there is frequently an extensive past psychiatric history (not least because these patients are often initially misdiagnosed as having DS). Characteristics of frontal lobe seizures that help distinguish them from DS are short ictal duration, stereotyped patterns of movements and occurrence during sleep (sometimes associated with secondary generalisation).

An opportunity to observe a seizure first hand and to examine the patient during a seizure may provide invaluable information. ${ }^{7282935}$ Careful note should be taken of the type of movements seen, their distribution, and whether apparent clonic movements are rhythmic and synchronous (as they usually are in epilepsy) or not (DS). After a generalised tonic clonic seizure the corneal reflex will usually be impaired and plantar responses extensor. If the patient's eyes are shut the examiner should attempt to open them and note any resistance to this (DS). A simple test to look for avoidance of a noxious stimulus is to hold the patients hand over their face and drop it: in DS the patient may be seen to control their arm movement so their hand falls to one side. If the eyes are open, evidence of visual fixation may be sought in two ways. The first entails rolling the patient onto their side. In a patient with DS the eyes will often be deviated to the ground. The patient should then be rolled onto the other side and note taken if the eyes are still directed towards the ground (the Henry and Woodruff sign). ${ }^{49}$ A second useful manoeuvre is to place a small mirror in front of the patient and look for evidence of convergent gaze and fixation on the reflection. This procedure may also prove useful in stopping the seizure. All of these examination findings must however be interpreted with caution: the "correct" response to any of these tests may be learned by patients who are simulating illness. Table 2 gives a checklist of examination procedures that may help differentiate DS from ES.

After careful clinical assessment the experienced clinician may often be in a position to reach a confident diagnosis. Sometimes, however, doubt remains, even if a seizure is witnessed: in one study an experienced epileptologist viewing videotapes of seizures correctly identified only $73 \%$ of DS and $71 \%$ of ES. ${ }^{38}$ Special investigations therefore have an important role in diagnosis but there are pitfalls and limitations that will be considered next.

Table 2 Checklist of examination procedures that may help differentiate dissociative seizures from epileptic seizures

\begin{tabular}{ll}
\hline Examination procedure & Finding in DS \\
\hline $\begin{array}{l}\text { Drop patient's hand over their face } \\
\text { If eyes closed, attempt to open them }\end{array}$ & $\begin{array}{l}\text { hand falls to the side } \\
\text { resistance to eye opening } \\
\text { If eyes open } \\
\text { Place mirror in front of patient }\end{array}$ \\
$\begin{array}{l}\text { Roll patient from one side to the other } \\
\text { (Henry and Woodruff sign, } \\
\text { see text) } \\
\text { intact neurological reflexes }\end{array}$ \\
$\begin{array}{l}\text { Corneal reflex } \\
\text { Plantar reflex }\end{array}$ \\
$\begin{array}{l}\text { The findings in the first three tests suggest some preservation of intact } \\
\text { awareness and volition. By general consensus, however, these } \\
\text { examination findings should not be interpreted as proving the patient is } \\
\text { fabricating their illness. As a cautionary note, some patients may learn to } \\
\text { produce the "correct" neurological response with any of these } \\
\text { examinations. }\end{array}$
\end{tabular}




\section{SPECIAL INVESTIGATION EEG}

According to Chadwick ${ }^{50}$ the EEG is "one of the most abused investigations in clinical medicine and is unquestionably responsible for great human suffering". While a single routine EEG may be normal in some $30 \%$ of patients with epilepsy (the false negative rate falls to around $15 \%$, or even less in patients with repeated studies or sleep recordings ${ }^{51}$ ) Chadwick was highlighting the problem of false positives. Anything up to $15 \%$ of the normal population may have a "non-specific" abnormality noted on EEG. There is clearly a danger both that an EEG may be "over reported", especially if the request form sent to the electrophysiologist expresses no doubt about the diagnosis, and also that such non-specific abnormalities might be misunderstood by inexperienced clinicians as backing a diagnosis of epilepsy when they do no such thing. This problem is compounded by the fact that such non-specific abnormalities (principally a slow background rhythm) are more common in patients with DS than in healthy volunteers ${ }^{52}$ and in patients with borderline personality disorder, ${ }^{53}$ which is common in patients with DS (see below). It should be noted, however, that rigorously defined specific "epileptiform" abnormalities (generalised spikes or polyspike and slow wave abnormalities) are very rare (about 3 in 1000) in healthy people. ${ }^{54}{ }^{55}$ The EEG is just one factor that must be weighed up in making a diagnosis of epilepsy that ultimately rests on clinical judgement.

\section{Video EEG telemetry}

The gold standard investigation for seizure disorders is long term monitoring with video EEG (vEEG) telemetry. The patient is admitted to hospital with the aim of catching a seizure (ideally more than one) on both video and EEG, allowing the semiology of the seizure to be observed and providing an ictal EEG recording. The critical EEG findings ${ }^{7}$ include ictal epileptiform discharges (which may be obscured or even mimicked by movement artefact) and post-ictal slowing of the background rhythm. An important sign that excludes organic causes of unconsciousness is the presence of an intact alpha rhythm (a neurophysiological correlate of alertness most prominent when the patient's eyes are closed) in an unresponsive patient. Aside from practical considerations (vEEG telemetry is an expensive investigation and is not widely available) there are also some important clinical limitations. Firstly, the ictal scalp EEG is often normal in simple partial seizures (in which consciousness is preserved $)^{5657}$ and in frontal lobe seizures. ${ }^{478}$ As already discussed frontal lobe seizures are particularly problematic as they may include bizarre motor and behavioural manifestations and are often mistaken for DS. In these cases the video recording will often be extremely useful. A further helpful point is that frontal lobe seizures commonly arise from sleep and the ictal EEG will show this clearly even if there are no other electrographic signs of epilepsy. Although patients with DS often report seizures in sleep, when they are captured on telemetry they are inevitably preceded by waking, ${ }^{3}$ which again can be recorded electrographically. A more common problem concerns patients with seizures occurring so infrequently that they are unlikely to have an episode during telemetry. Patients with more than one type of seizure also require special attention. Because DS and ES often occur in the same patient care must be taken to ensure that a representative example of each seizure type has been captured. Occasionally patients with epilepsy may have a DS for the first time in their lives on a telemetry unit, perhaps brought on by the stress of admission to hospital and "performance anxiety" secondary to a perceived pressure to have an attack. $^{58}$ Thus, where possible someone who has witnessed the patient's seizures should be shown the video (with the patient's consent) to verify that the recorded attack is characteristic of the patient's habitual seizures.

Ambulatory EEG ${ }^{59}$ may be conducted as an outpatient but suffers from the disadvantage of having no video recorded semiology to correlate with the EEG. Asking a patient's carer to video seizures may also be very helpful with the accepted limitation that the first few seconds after seizure onset will usually be missed. In an attempt to reduce the need for long and costly telemetry several investigators have explored the possibility of provoking seizures through suggestion while obtaining video and EEG recordings. Using procedures such as intravenous infusion of saline up to $90 \%$ of patients will have a DS ${ }^{60}{ }^{61}$ but these methods remain controversial because of ethical concerns about the use of placebo. Most recently, however, McGonigal and colleagues ${ }^{62}$ combined simple suggestion with activation stimuli used routinely in EEG testing (photic stimulation and hyperventilation) and fully disclosed the aims of the procedure to patients. Sixty six per cent of patients experienced a DS provoked in this way compared with $33 \%$ in a control group who received identical activation stimuli but without suggestion. In these settings, because of very occasional false positive results in patients with epilepsy, ${ }^{63}{ }^{64}$ it is particularly important to have a witness confirm the provoked seizure as habitual.

\section{Serum prolactin}

Serum prolactin ${ }^{65}$ rises to concentrations greater than $500 \mathrm{IU} /$ $\mathrm{ml}$ in over $90 \%$ of patients after a tonic-clonic seizure and $60 \%$ of patients after a complex partial seizure. Simple partial seizures are not followed by a rise in serum prolactin and prolactin concentrations may be normal after prolonged status epilepticus. Blood must be taken between 20 and 30 minutes after the seizure and compared with a baseline sample. The test is, however, used less and less in specialist centres as false positive results have now been found in syncope $^{66}$ and DS. ${ }^{67}$ Thus, while a normal post-ictal prolactin may be helpful diagnostically if the seizure was tonic-clonic in semiology, an increased post-ictal prolactin is non-specific.

\section{PSYCHIATRIC ASSESSMENT OF PATIENTS WITH DS Conscious/unconscious symptom generation}

As we have seen, after organic diagnoses have been excluded and a primary psychiatric disorder that has been mistaken for epilepsy ruled out, the diagnostic possibilities are DS and factitious disorder. The distinction made between DS and factitious disorder in psychiatric classification systems implies a dichotomy between what is conscious and what is not. In practice the distinction may be difficult to make and a definite diagnosis of factitious disorder ultimately depends on the patient confessing their intent to deceive. The notion of unconscious symptom generation remains controversial ${ }^{68}$ and a more valid way of conceiving the problem might be as a continuum with unconscious motivation at one end, conscious simulation at the other, and a large grey area in between, with "self deception" lying somewhere in the middle.

Most authorities suggest that most patients are unconscious of any wilful component to their seizures and factitious disorder is held to be rare. ${ }^{37}{ }^{65}$ However, many find this hard to accept. Three points in favour of the symptoms being unconscious are worth considering, although none is by any means conclusive: (1) most patients are compliant with antiepileptic medication, often for several years and to the point of toxicity, until the correct diagnosis is made; (2) when admitted for EEG telemetry most patients have a seizure within what they must surely perceive to be an intensively monitored setting; (3) DS are generally a poor imitation of epilepsy. In fact, factitious disorder will often be suspected whenever one of these three conditions is not met. 
Psychiatric formulation: epidemiological consideration, comorbidity, and risk factors for DS Psychiatric assessment should aim to identify putative risk factors for DS that may help the patient understand why they have the disorder and may direct psychological and other approaches to treatment. What follows is an account of the demographic characteristics of DS and possible predisposing and maintaining factors identified in the literature.

About three quarters of patients are women. ${ }^{793669}$ Seizures usually begin in the late teens or early 20 s but there is a wide range. ${ }^{79}{ }^{36}$ Patients in lower socioeconomic groups and with less educational achievement are probably over-represented, although not in comparison with patients with epilepsy. ${ }^{69}$

A history of previous medically unexplained symptoms is present in up to $80 \%$ of patients..$^{764170}$ In some cases symptoms will have attracted a medical diagnosis although objective evidence of pathology is lacking. The recently reported association of a diagnosis of asthma in patients with DS may be an example of this. ${ }^{36}{ }^{71}$ In addition to a history suggestive of somatisation, there is a high rate of psychiatric comorbidity. Maladaptive personality features of a borderline type are common, ${ }^{72}$ often in the form of trait accentuations rather than personality disorder in itself..$^{73}$ Related to this, patients with DS show less adaptive coping styles. ${ }^{75}{ }^{76}$ Comorbid anxiety disorders and depression have been widely reported ${ }^{36}$ but prevalence rates vary between studies and have often not been strikingly greater than seen in patients with epilepsy in those studies that have used a control group..$^{72} 73$

The prevalence of abnormal personality in these patients suggests adverse experiences occurring in childhood or adolescence at a time when personality attributes are developing, and the risk factor to have attracted most attention in the literature is a history of childhood abusive experiences. Although there have been negative findings, ${ }^{78} 79$ a number of large studies in which abuse has been carefully defined have shown higher rates of reported abuse in patients with DS compared with epileptic controls and unselected psychiatric patients. ${ }^{698} 81$ Traumatic, abusive experiences in adulthood have also been implicated. ${ }^{81}$ Other traumatic experiences or situations that foster low self esteem, for example bullying at school or unrecognised learning difficulties, ${ }^{82}$ may be over-represented but have not been studied in adults with DS.

There is evidence that adverse life events are more common in the year preceding onset of $\mathrm{DS}^{72}$ but triggers for initial seizures are often not apparent. Adverse family interactions ${ }^{83-85}$ may serve both as predisposing and maintaining factors for DS. A pattern of avoidant behaviour, often exacerbated by carers' overprotective reactions, is a comparatively underrecognised maintaining factor but readily apparent on history taking in the form of an agoraphobic pattern of avoidance ostensibly for fear of having a seizure in an embarrassing or vulnerable setting. ${ }^{84}$ Finally, for some patients the psychological and social advantages inherent to a medical sick role are undoubtedly important maintaining factors. ${ }^{968} 87$ Such advantages include both an avoidance of responsibility and positive benefits such as the caring response elicited in others.

It should be noted that DS share many possible aetiological factors with other somatoform disorders. The paroxysmal nature of the symptoms, however, gives this disorder a unique quality that creates special difficulties for diagnosis but also raises specific treatment approaches.

\section{TREATMENT}

\section{Explaining the diagnosis to patients}

Treatment begins with an explanation of diagnosis. This must be handled openly but sensitively: if it is not, the patient is likely to reject the diagnosis, decline treatment, and go elsewhere for more investigations; a disaster in terms of time and expense, both for the patient and medical services. ${ }^{88} 89$

\section{PRESENTING THE DIAGNOSIS OF DISSOCIATIVE SEIZURES}

In discussing the diagnosis with the patient the following points should be covered:

(1) Reasons for concluding they do not have epilepsy

(2) What they do have (describe dissociation)

(3) Emphasise they are not suspected of "putting on" the attacks

(4) They are not "mad"

(5) Triggering "stresses" may not be immediately apparent.

(6) Relevance of aetiological factors in their case

(7) Maintaining factors

(8) May improve after correct diagnosis

(9) Caution that AED withdrawal should be gradual

(10) Describe psychological treatment

It is important to involve patients' carers in this explanation.

Firstly, a clear explanation must be given of the reasons for concluding that the patient does not have epilepsy. This should cover any aspects of the patient's seizure semiology that are inconsistent with epilepsy and features in their history that make epilepsy less likely (for example, a failed response to AEDs, lack of risk factors for epilepsy). A thorough explanation of investigation results should follow that, if relevant, must address any non-specific "abnormalities" that the patient may previously have been told about and the way in which these can be put in context.

A description of what the patient does have then follows. Many patients will react unfavourably to the news that no medical explanation has been found and great care should be taken to emphasise that the doctor understands the attacks are real, disabling, and that the patient is not suspected of putting them on. A useful approach can be to tell the patient that they have attacks in which their mind or brain "switches off", involuntarily, and they lose control. It is often helpful to describe the concept of dissociation, explaining that the attacks represent an extreme form of something that is part of everyday experience using examples illustrating selective and divided attention (for example, reading a book and not hearing your name called, travelling home from work and remembering nothing of the journey). It should be explained that the symptoms are stress related but that it is usual for the stresses to be difficult to identify. Patients commonly object that the seizures cannot be caused by stress as they occur at times when they are relaxed. In this situation it may be helpful to explain that attacks may be triggered by stressful or unpleasant thoughts that the patient is barely aware of (or cannot remember) and may have little to do with their immediate circumstances. The concept that thinking may occur on a number of different levels at any one time can be described. Examples of the link between physical symptoms and emotional state (for example, crying, autonomic symptoms of arousal) and complex involuntary behavioural accompaniments to emotions (for example, as seen with sudden grief or with rage) may help illustrate some of the physical attributes of seizures. If the patient experiences somatic symptoms of arousal during their seizures $^{90}$ the relation of these features to anxiety can be described and the seizures likened to a "panic attack without the panic" in which dissociation ("switching off") protects the patient from unpleasant or frightening emotions.

Patients often express a fear that they are being told they are "mad". They should be reassured that the condition they 
have is common and the profile of a typical patient should be described, emphasising the points that apply to them. A link between traumatic experiences in childhood may be made meaningful by explaining that children exposed to abuse, especially if it is repeated, learn to "switch off" as a way of coping: DS may represent a re-emergence of this once adaptive response in the face of challenges, stress, or perhaps something that reminds the patient of painful memories. Some $^{88}$ have recommended raising the subject of abuse as a causal factor even if a history of it has not emerged. However, such an approach risks encouraging "false memories" and may best be avoided.

A description of maintaining factors is important and is often welcomed by patients who are sceptical about supposed psychological origins of their symptoms. It can be explained that whatever caused the seizures in the first place may remain unknown, but that worry about seizures, including what they are attributable to, and worry about the consequences of having a seizure may actually make the seizures worse and more frequent. ${ }^{91}$ Patients will often relate to the confusion and anxiety engendered by receiving contradictory advice from a succession of doctors and the role this may have in perpetuating attacks. The concept of how avoidant behaviour, often exacerbated by a well meaning family's protective reactions, acts to reinforce anxiety about attacks ${ }^{91}$ may give the patient and their family a rationale for change.

Finally, the patient should be given hope that their problems are treatable. Most patients are delighted to hear they may discontinue AEDs but they should be warned that this must be done gradually for fear of triggering a withdrawal seizure. It is worth emphasising that once confusion about diagnosis is resolved a significant proportion of patients find that this explanation alone leads to a resolution of the attacks over time. ${ }^{92}$

\section{Approaches to treatment}

There have been no controlled trials of treatment in DS. The evidence comes from case reports and small treatment

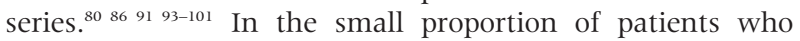
have significant comorbid depression or anxiety appropriate pharmacotherapy is indicated. For most, however, some form of psychotherapy will be the mainstay of treatment. In patients with learning difficulties operant behavioural programmes using simple reward systems are often helpful. ${ }^{94}{ }^{95}$ The early literature includes a number of compelling descriptions of insight oriented, dynamic psychotherapeutic approaches in patients with a history of DS and sexual abuse. ${ }^{98} 99$ More recent reports have described psychoeducational group therapy ${ }^{100}$ and eye movement desensitisation ${ }^{101}$ in similar patient groups. Variations of therapy based on psychodynamic, insight oriented, and educational principles are undoubtedly widely practised and believed to be effective but further studies of such interventions are needed.

The paroxysmal nature of the attacks, the occurrence of somatic symptoms of arousal in many patients, and the association with agoraphobic avoidant behaviour suggest that techniques developed in cognitive behavioural therapy (CBT) for the treatment of panic disorder might readily be adapted for DS. ${ }^{86}$ This CBT model also provides a useful rationale for treatment in patients who report no history of past traumatic experiences or who have received psychotherapy for this but continue to have seizures. A recent study involving 20 patients treated with CBT reported a significant reduction in seizures six months after treatment ended and, perhaps more importantly, found improvements in work and social outcome. ${ }^{86}$ CBT techniques developed for personality disorder may be helpful but these and other techniques require evaluation. ${ }^{102} \mathrm{~A}$ significant proportion (see below) of patients continue to have seizures despite intensive and varied treatment. A realistic approach in such cases is to offer long term follow up to provide support for the patient and their family, social interventions to improve quality of life despite seizures, and also to limit the cost and morbidity associated with further unnecessary investigations and medical interventions.

\section{Outcome}

A recent review of outcome studies ${ }^{27}$ found that after a mean follow up period of three years about two thirds of patients continued to have DS and more than half remained dependent on social security. Receiving psychiatric treatment has been associated with a positive outcome in some studies, but not in others. A poor prognosis is predicted by a long delay in diagnosis and the presence of psychiatrc comorbidity, including personality disorder.

Funding: none.

Conflicts of interest: none.

\section{REFERENCES}

1 Leis AA, Ross MA, Summers AK. Psychogenic seizures: ictal characteristics and diagnostic piffalls. Neurology 1992;42:95-9.

2 Thacker K, Devinsky O, Perrine K, et al. Nonepileptic seizures during apparent sleep. Ann Neurol 1993;33:414-18.

3 Smith D, Defalla BA, Chadwick DW. The misdiagnosis of epilepsy and the management of refractory epilepsy in a specialist clinic. QJM 1999;92:15-23

4 Benbadis SR, Allen HW. An estimate of the prevalence of psychogenic nonepileptic seizures. Seizure 2000;9:280-1.

5 Kotsopoulos IA, de Krom MC, Kessels AG, et al. The diagnosis of epileptic and non-epileptic seizures. Epilepsy Res 2003;57:59-67.

6 Reuber M, Fernandez G, Baver J, et al. Diagnostic delay in psychogenic nonepileptic seizures. Neurology 2002;58:493-5.

7 Meierkord H, Will B, Fish D, et al. The clinical features and prognosis of pseudoseizures diagnosed using video-EEG telemetry. Neurology 1991;41:1643-6.

8 Krumholz A, Neidermeyer E. Psychogenic seizures: a clinical study with follow-up data. Neurology 1983;33:498-502.

9 Kristensen 0, Alving J. Pseudseizures - risk factors and prognosis. Acta Neurol Scand 1992;85:177-80.

10 Walker MC, Howard RS, Smith SJ, et al. Diagnosis and treatment of status epilepticus on a neurological intensive care unit. QJM 1996:89:913-20.

11 Stone J, Campbell K, Sharma N, et al. What should we call pseudoseizures? The patient's perspective. Seizure 2003;12:568-72.

12 Scull DA. Pseudoseizures or non-epileptic seizures (NES); 15 synonyms. J Neurol Neurosurg Psychiatry 1997;62:200.

13 American Psychiatric Association. Diagnostic and statistical manual of mental disorders (4th edition-DSM-IV). Washington DC: American Psychiatric Association, 1994.

14 World Health Organisation. The ICD-10 classification of mental and behavioural disorders. Clinical description and diagnostic guidelines. Geneva: World Health Organisation, 1992.

15 Martin RC, Gilliam FG, Kilgore M, et al. Improved health care resource utilization following video-EEG-confirmed diagnosis of nonepileptic psychogenic seizures. Seizure 1998;7:385-90.

16 Cook M. Differential diagnosis of epilepsy. In: Shorvorn S, Perucca E, Fish D, et al, eds. The treatment of epilepsy. 2nd ed. Oxford: Blackwell, 2004:64-73.

17 Andermann F. Non-epileptic paroxysmal neurologic events. In: Gater JR, Rowan AJ, eds. Non-epileptic seizures. 2nd ed. Boston: Butterworth Heinemann, 2000:51-69.

18 Lempert T, Baver M, Schmidt D. Syncope: a videometric analysis of 56 episodes of transient cerebral hypoxia. Ann Neurol 1994;36:233-7.

19 Sheldon R, Rose S, Ritchie D, et al. Historical criteria that distinguish syncope from seizures. J Am Coll Cardiol 2002;40:142-8.

20 Lempert T. Recognizing syncope: piffalls and surprises. J R Soc Med 1996;89:372-5

21 Parker C. Complicated migraine syndromes and migraine variants. Pediatr Ann 1997;26:417-21.

22 Manford MR, Fish DR, Shorvon SD. Startle provoked epileptic seizures:features in 19 patients. J Neurol Neurosurg Psychiatry 1996;61:151-6

23 Vidailhet M. Paroxysmal dyskinesias as a paradigm of paroxysmal movement disorders. Curr Opin Neurol 2000;13:457-62.

24 Schenck $\mathrm{CH}$, Mahowald MW. Parasomnias. Managing bizarre sleep-related behaviour disorders. Postgrad Med 2000;107:145-56.

25 Alper K, Devinsky O, Perrine K, et al. Psychiatric classification of nonconversion nonepileptic seizures. Arch Neurol 1995;52:199-201.

26 Toni C, Cassano GB, Perugi G, et al. Psychosensorial and related phenomena in panic disorder and in temporal lobe epilepsy. Compr Psychiatry 1996;37:125-33.

27 Reuber M, Elger CE. Psychogenic nonepileptic seizures: review and update. Epilepsy and Behavior 2003;4:205-16. 
28 Gulick TA Spinks IR, King DW. Pseudoseizures: ictal phenomena. Neurology 1982;32:24-30.

29 Gates JR, Ramani V, Whalen S, et al. Ictal characteristics of pseudoseizures. Arch Neurol 1985:42:1183-7.

30 Bazil CW, Walczak TS. Effects of sleep and sleep stage on epileptic and nonepileptic seizures. Epilepsia 1997;38:56-62

31 Desai BT, Porter RJ, Penry JK. Psychogenic seizures. A study of 42 attacks in 6 patients, with intensive monitoring. Arch Neurol 1982;39:202-9.

32 Wilkus RJ, Dodrill CB. Thompson PM. Intensive EEG monitoring and psychological studies of patients with pseudoepileptic seizures. Epilepsia 1984;25:100-7

33 Holmes GL, Sackellares JC, McKiernan J, et al. Evaluation of childhood pseudoseizures using EEG telemetry and video tape monitoring. J Pediatr 1980;97:554-8.

34 Lancman ME, Asconape JJ, Graves S, et al. Psychogenic seizures in children: long-term analysis of 43 cases. J Child Neurol 1994;9:404-7.

35 Luther JS, McNamara JO, Carwile S, et al. Pseudoepileptic seizures: methods and video analysis to aid diagnosis. Ann Neurol 1982;12:458-462

36 Bowman ES, Markand ON. Psychodynamics and psychiatric diagnoses of pseudoseizure subjects. Am J Psychiatry 1996;153:57-63.

37 Betts T, Boden S. Diagnosis, management and prognosis of a group of 128 patients with non-epileptic attack disorder. Part 1. Seizure 1992;1:19-26.

38 King DW, Gallagher BB, Murvin AJ, et al. Pseudoseizures: diagnostic evaluation. Neurology 1982;32:18-23.

39 DeToledo JC, Ramsey RE. Patterns of involvement of facial muscles during epileptic and nonepileptic events: review of 654 events. Neurology 1996;47:621-5

40 Geyer JD, Payne TA, Drury I. The value of pelvic thrusting in the diagnosis of seizures and pseudoseizures. Neurology 2000;54:227-9.

41 Lempert T, Schmidt D. Natural history and outcome of psychogenic seizures: a clinical study in 50 patients. J Neurol 1990;237:35-8.

42 Bergen D, Ristanovic R. Weeping as a common element of pseudoseizures. Arch Neurol 1993;50:1059-60.

43 Walczak T, Bogolioubov A. Weeping during psychogenic nonepileptic seizures. Epilepsia 1996;37:208-10.

44 Cohen RJ, Suter C. Hysterical seizures: suggestion as a provocative EEG test. Ann Neurol 1982;11:391-5.

45 Commission on Classification and Terminology of the International League Against Epilepsy. Proposal for revised classification of epilepsies and epileptic syndromes. Epilepsia 1989;30:389-99.

46 Moore PM, Baker GA. Non-epileptic attack disorder: a psychological perspective. Seizure 1997;6:429-34

47 Williamson PD, Spencer DD, Spencer SS, et al. Complex partial seizures of frontal lobe origin. Ann Neurol 1985;18:497-504.

48 Saygi S, Katz A, Marks DA, et al. Frontal lobe partial seizures and psychogenic seizures: comparison of clinical and ictal characteristics. Neurology 1992;42:1274-7.

49 Henry J, Woodruff GAJ. A diagnostic sign in states of apparent unconsciousness. Lancet 1978;ii:920-1.

50 Chadwick D. Epilepsy. J Neurol Neurosurg Psychiatry 1994;57:264-77.

51 Binnie CD, Prior PF. Electroencephalography. J Neurol Neurosurg Psychiatry 1994:57:1308-19.

52 Reuber M, Fernandez G, Baver J, et al. Interictal EEG abnormalities in patients with psychogenic non-epileptic seizures. Epilepsia 2002;43:1013-20.

53 De la Fuente, Tugendhaft P, Mavroudakis. Electroencephalographic abnormalities in borderline personality disorder. Psychiatry Res 1998;77:131-8.

54 Robin JJ, Tolan JD, Arnold JW. Ten-year experience with abnormal EEGs in asymptomatic adult males. Aviat Space Environ Med 1978;49:732-6.

55 Gregory RP, Oates T, Merry RTG. Electroencephalogram epileptiform abnormalities in candidates for aircrew training. Electroencephalogr Clin Neurophysiol 1993;86:75-7.

56 Devinsky O, Kelley K, Porter RJ, et al. Linical and electrographic features of simple partial seizures. Neurology 1988;18:1347-52.

57 Bare MA, Burnstine TH, Fisher RS, et al. Electroencephalographic changes during simple partial seizures. Epilepsia 1994;35:715-20.

58 Kapur J, Pillai A, Henry TR. Psychogeic elaboration of simple partial seizures. Epilepsia 1995;36:1126-30.

59 Cascino GD. Video-EEG monitoring in adults. Epilepsia 2002;43(suppl 3): 80-93.

60 Slater JD, Brown M, Jacobs W. Induction of pseudoseizures with intravenous saline placebo. Epilepsia 1995;36:580-5.

61 Dericioglu N, Saygi S, Ciger A. The value of provocation methods in patients suspected of having non-epileptic seizures. Seizure 1999;8:152-6.

62 McGonigal A, Oto M, Russell AJC, et al. Outpatient video EEG recording in the diagnosis of non-epilepstic seizures: a randomised controlled trial of simple suggestion techniques. J Neurol Neurosurg Psychiatry 2002;72:549-51.

63 Walczak TS, Williams DT, Berten W. Utility and reliability of placebo infusion in the evaluation of patients with seizures. Neurology 1994;44:394-9.

64 Barry JJ, Atzman O, Morrell MJ. Discriminating between epileptic and nonepileptic events: the utility of hypnotic seizure induction. Epilepsia 2000:41:81-4.

65 Trimble MR. Pseudoseizures. Neurol Clin 1986;4:531-47.

66 Oribe E, Amini R, Nissenbaum E, et al. Serum prolactin concentrations are elevated following syncope. Neurology 1996;47:60-62.

67 Alving J. Serum prolactin levels are elevated also after pseudo-epileptic seizures. Seizure 1998;7:85-9.
68 Slavney PR. In defense of pseudoseizure. Gen Hosp Psychiatry 1994: 16:243-5

69 Alper K, Devinsky O, Perrine K, et al. Nonepileptic seizures and childhood sexual and physical abuse. Neurology 1993;43:1950-3.

70 Walczak TS, Papacostas S, Williams DT, et al. Outcome after diagnosis of psychogenic nonepileptic seizures. Epilepsia 1995;36:1131-7.

71 de Wet CJ, Mellers JD, Gardner WN, et al. Pseudoseizures and asthma J Neurol Neurosurg Psychiatry 2003;74:639-41.

72 Binzer M, Stone J, Sharpe M. Recent onset pseudoseizures-clues to aetiology. Seizure 2004;13:146-55.

73 Krishnamoorthy ES, Brown RJ, Trimble MR. Personality and psychopathology in nonepileptic attack disorder and epilepsy: a prospective study. Epilepsy and Behaviour 2001;2:418-22.

74 Reuber M, Pukrop R, Bauer J, et al. Multidimensional assessment of personality in patients with psychogenic non-epileptic seizures. J Neurol Neurosurg Psychiatry 2004;75:743-8.

75 Frances PL, Baker GA, Appleton PL. Stress and avoidance in pseudoseizures: testing the assumptions. Epilepsy Res 1999;34:241-9.

76 Goldstein LH, Drew C, Mellers J, et al. Dissociation, hypnotizability, coping styles and health locus of control: characteristics of pseudoseizure patients. Seizure 2000;9:314-22.

77 van Merode T, Twellaar M, Kotsopoulos IA, et al. Psychological characteristics of patients with newly developed psychogenic seizures. J Neurol Neurosurg Psychiatry 2004;75:1175-7.

78 Jawad SS, Jail N, Clarke EJ, et al. Psychiatric morbidity and psychodynamics of patients with convulsive pseudoseizures. Seizure 1995;4:201-6.

79 Tojek TM, Lumley M, Barkley G, et al. Stress and other psychosocial characteristics of patients with psychogenic nonepileptic seizures. Psychosomatics 2000:41:221-6.

80 Betts T, Boden S. Diagnosis, management and prognosis of a group of 128 patients with non-epileptic attack disorder. Part 1. Previous childhood sexual abuse in the aetiology of these disorders. Seizure 1992;1:27-32.

81 Reilly J, Baker GA, Rhodes J, et al. The association of sexual and physical abuse with somatization: characteristics of patients presenting with irritable bowel syndrome and non-epileptic attack disorder. Psychol Med 1999;29:399-406

82 Silver LB. Conversion disorder with pseudoseizures in adolescence: a stress reaction to unrecognized and untreated learning disabilities. J Am Acad Child Psychiatry 1982;21:508-12.

83 Moore PM, Baker GA, McDade G, et al. Epilepsy, pseudoseizures and perceived family characteristics: a controlled study. Epilepsy Res 1994; 18:75-83

84 Krawetz P, Fleisher W, Pillay N, et al. Family functioning in subjects with pseudoseizures and epilepsy. J Nerv Ment Dis 2001;189:38-43.

85 Stanhope N, Goldstein LH, Kuipers E. Expressed emotion in the relatives of people with epileptic or nonepileptic seizures. Epilepsia 2003:44:1094-102.

86 Goldstein LH, Deale AC, Mitchell-O'Malley S, et al. An evaluation of cognitive behavioral therapy as a treatment for dissociative seizures. A pilot study. Cognitive and Behavioral Neurology 2004;17:41-9.

87 Slavney PR. Pseudoseizures, sexual abuse and hermeneutic reasoning. Compr Psychiatry 1994:35:471-7.

88 Shen W, Bowman ES, Markand O. Presenting the diagnosis of pseudoseizure. Neurology 1990;40:756-9.

89 Carton S, Thompson PJ, Duncan JS. Non-epileptic seizures: patients understanding and reaction to the diagnosis and impact on outcome. Seizure 2003; 12:287-94.

90 Vein AM, Djukova GM, Vorobieva OV. Is panic attack a mask of psychogenic seizures? - a comparative analysis of phenomenology of psychogenic seizures and panic attacks. Funct Neurol 1994;9:153-9.

91 Chalder T. Non-epileptic attacks: A cognitive behavioural approach in a single case approach with a four-year follow-up. Clinical Psychology and Psychotherapy 1996;3:291-7

92 Farias ST, Thieman C, Alsaadi TM. Psychogenic nonepileptic seizures: acute change in event frequency after presentation of the diagnosis. Epilepsy and Behaviour 2003:4:424-9.

93 Ramani V, Gumnit RJ. Management of hysterical seizures in epileptic patients. Arch Neurol 1982;39:78-81

94 Montgomery JM, Espie CA. Behavioural management of hysterical pseudoseizures. Behavioural Psychotherapy 1986;14:334-40.

95 Lachenmeyer JR, Olsen ME. Behaviour modification in the treatment of pseudoseizures: a case report. Behavioural Psychotherapy 1990;18:73-8.

96 Gates JR. Nonepileptic seizures: classification, coexistence with epilepsy, diagnosis, therapeutic approaches and consensus. Epilepsy and Behaviou 2002;3:28-33.

97 Iriarte J, Parra J, Urrestarzu $\mathrm{E}$, et al. Controversies in the diagnosis and management of psychogenic pseudoseizures. Epilepsy and Behaviour 2003;4:354-9.

98 Goodwin J, Simms M, Bergman R. Hysterical seizures: a sequel to incest. Am J Orthopsychiatry 1979;49:698-703.

99 Gross M. Pseudoepilepsy: a study in adolescent hysteria. Am J Psychiatry 1979;136:210-13

100 Zaroff CM, Myers L, Bar WB, et al. Group psychoeducation as treatment for psychological nonepileptic seizures. Epilepsy and Behaviour 2004;5:587-92.

101 Chemali Z, Meadows M. The use of eye movement desensitization and reprocessing in the treatment of psychogenic seizures. Epilepsy and Behaviour 2004;5:784-7.

102 Goldstein LH. Assessment of patients with psychogenic non-epileptic seizures: psychogenic non-epileptic seizures pose a management problem. J Neurol Neurosurg Psychiatry 2004;75:667-8. 